\title{
Current Perspectives on Physician Barriers to Breast Cancer Screening
}

\author{
Dorotby S. Lane, MD, MPH, and Catberine R. Messina, $M A$
}

Background: Despite reports of rising mammography utilization, breast cancer screening rates still lag behind national recommendations and goals, particularly for older women. This study explores current modifiable physician barriers to screening.

Methods: Family physicians and internists on the staff of 10 Long Island community hospitals were surveyed during three successive waves $(1988,1990,1995)$ about breast cancer screening behavior. The final survey also assessed current attitudes and level of confidence in screening abilities and beliefs relating to cancer risk and screening of the elderly.

Results: The proportion of physicians reporting regularly referring all women aged 50 to 75 years for mammography increased significantly from 37 percent (1988) to 64 percent (1995), while the proportion reporting regularly performing clinical breast examinations remained stable at 56 percent. More than 25 percent of respondents to the 1995 survey were not aware that breast cancer risk increases with aging, and more than one half did not recognize that breast cancer detection by mammography is enhanced in older postmenopausal women. Some physicians reported lack of confidence in aspects of patient counseling, examination, and use of office systems to promote screening.

Conclusion: Continuing medical education programs addressing knowledge deficits and perceived physician needs for enhancement of clinical breast examination skills are needed to promote continued improvement in inadequate mammography screening rates. (J Am Board Fam Pract 1999;12:8-15.)

During the past decade there has been evidence of underutilization of mammography among women 50 years of age or older for whom all major national groups, including federal agencies (National Institutes of Health, Office of Disease Prevention and Health Promotion), the American Cancer Society, and several medical specialty societies (eg, American Academy of Family Physicians, American College of Physicians, American College of Obstetrics and Gynecology, American College of Preventive Medicine), recommend screening. The critical role of the primary care physician in promoting screening has been documented, and missed opportunities to refer for mammography screening at the time of performance of the clinical breast examination have been described. ${ }^{1}$ Related evidence is the lack of adherence to national breast cancer screening recommendations by a considerable proportion of primary care physicians, partic-

Submitted, revised, 13 May 1998.

From the Department of Preventive Medicine (DSL, CRM), State University of New York at Stony Brook. Address reprint requests to Dorothy $\mathrm{S}$. Lane, $M D, M P H$, School of Medicine, HSC 4-181, State University of New York at Stony Brook, Stony Brook, NY 11794-8437.

This research was supported under grants ROICA45034 and RO1CA60129 from the National Cancer Institute. ularly internists and family physicians, compared with obstetrician-gynecologists. ${ }^{2-6}$ The purpose of this study is to describe remaining barriers to improved screening. We begin by reporting on trends in the breast cancer screening practices of community physicians during an 8-year period (1988 to 1995). In addition, we include changes in attitude and behavior concerning the role of mammography in breast cancer screening as well as physician self-assessment of screening skills. This information can provide direction for continuing medical education in breast cancer screening.

\section{Methods}

Primary care physician surveys were conducted in conjunction with our National Cancer Institute (NCI) supported projects to increase physician referral for breast cancer screening and increase use among women 50 years of age and older. These two succeeding projects (Awareness of Breast Cancer Screening and Early Detection Guidelines Education) are part of the NCI Breast Cancer Screening Consortium. In each of three survey years-1988, 1990, and 1995-a combined approach to physician survey was used, which involved distributing and collecting the survey in- 
strument at community hospital department meetings in family practice and internal medicine within 10 hospitals in four study communities on Long Island. The study was restricted to these primary care specialties because of baseline evidence that adherence to screening recommendations was high among obstetrician-gynecologists. ${ }^{2-6}$

Three mailed attempts were made to reach physicians in family practice and general internal medicine who were on the staff of these 10 hospitals and who were nonrespondents or not in attendance at the hospital meetings. The physicians included all those in family practice or internal medicine who were in active practice in these communities. The last mailing was sent certified mail. There was no financial incentive for completing the survey.

The response rates for each of the 3 years were as follows: 72 percent (1988), 69 percent (1990), 66 percent (1995). Questionnaires completed by internal medicine subspecialists were not included in the analyses. To rule out a bias introduced by declining response rates, an additional analysis was performed which assumed the worst-case scenario that all nonrespondents were nonadherers. The small (8 percent) decrease in response rate was found to account for very little inflation in the reported increase in referrals, which even with this worst-case scenario analysis still improved by more than 50 percent.

The survey instrument collected data on physician characteristics, breast cancer screening practices, and attitudes relating to the efficacy of mammography and clinical breast examination. Changes in physicians' self-reported mammography referral and clinical breast examination performance were followed in each of the three survey waves. The 1988 and 1995 surveys were baseline surveys of both intervention and control group physicians who were unaware of the proposed subsequent interventions. While the 1990 survey data was postintervention, the data used also included both intervention and control group physicians. To rule out any response bias relating to recollection of past interventions by physicians in the intervention group, an additional analysis was performed on control group physicians only.

Current attitudes and levels of confidence relating to breast cancer screening skills were explored in depth in the most recent survey (1995), which also included questions relating to risk factors and
Table 1. Physician Characteristics (Percent) by Survey Year.

\begin{tabular}{|c|c|c|c|}
\hline \multirow[b]{2}{*}{ Characteristic } & \multicolumn{3}{|c|}{ Survey Year } \\
\hline & $\begin{array}{c}1988 \\
(n=399)\end{array}$ & $\begin{array}{c}1990 \\
(\mathrm{n}=363)\end{array}$ & $\begin{array}{c}1995 \\
(n=426)\end{array}$ \\
\hline \multicolumn{4}{|l|}{ Sex } \\
\hline Male & 88.1 & 88.7 & 85.0 \\
\hline Female & 11.9 & 11.3 & 14.6 \\
\hline \multicolumn{4}{|l|}{$A g e^{*}$} \\
\hline$\leq 44$ years & 45.0 & 45.8 & 38.8 \\
\hline $45-64$ years & 46.0 & 45.3 & 44.9 \\
\hline$\geq 65$ years & 9.0 & 8.9 & 16.3 \\
\hline \multicolumn{4}{|l|}{ Graduated from medical scboolt } \\
\hline$\leq 10$ years ago & 21.9 & 22.9 & 12.4 \\
\hline $11-20$ years ago & 26.7 & 27.2 & 28.8 \\
\hline 21 - 30 years ago & 24.3 & 23.5 & 18.5 \\
\hline $31-40$ years ago & 19.2 & 18.6 & 24.6 \\
\hline$>40$ years ago & 8.0 & 7.7 & 15.6 \\
\hline \multicolumn{4}{|l|}{ Specialty } \\
\hline Family medicine & 38.8 & 44.6 & 44.3 \\
\hline Internal medicine & 61.2 & 55.4 & 55.6 \\
\hline \multicolumn{4}{|l|}{ Practice type } \\
\hline Private solo & 56.4 & 57.5 & 58.8 \\
\hline Private group & 29.1 & 30.2 & 29.9 \\
\hline Prepaid group & 2.3 & 1.1 & 3.8 \\
\hline Full-time hospital & 6.4 & 5.2 & 5.0 \\
\hline Public health center & 2.6 & 4.3 & 1.7 \\
\hline Other & 3.3 & 1.7 & 0.9 \\
\hline Participate in managed care & - & - & 81.9 \\
\hline
\end{tabular}

${ }^{*} \chi^{2}=4.5,1 d f, P<0.05$ (Mantel-Haenszel test for linear association).

${ }^{\dagger} \chi^{2}=7.1,1 d f, P<0.01$ (Mantel-Haenszel test for linear association). ¥Question asked only in 1995 .

to breast cancer screening in the elderly. The Mantel-Haenszel chi-square test for linear association (1 degree of freedom $)^{7}$ was used to determine the statistical significance of changes with time. Analyses were performed using the Statistical Package for the Social Sciences (SPSS). ${ }^{8}$

\section{Results}

As indicated in Table 1, the demographic characteristics of the physician respondents remained stable during the 8-year period, except for an increase in the proportion of older physicians and, related to this finding, earlier graduation from medical school. The predominant practice type was private solo practice, and 82 percent of the physicians reported in 1995 that they participated in managed care.

There was a statistically significant $(P<0.001)$ increase in the proportion of primary care physi- 
Table 2. Physician Reporting of Regular Screening of Asymptomatic Female Patients Aged 50 to 75 Years.

\begin{tabular}{|c|c|c|c|c|c|c|}
\hline \multirow[b]{2}{*}{$\begin{array}{l}\text { Percent } \\
\text { Referred or } \\
\text { Examined }\end{array}$} & \multicolumn{3}{|c|}{ Mammography Referral ${ }^{\star}$} & \multicolumn{3}{|c|}{ Breast Examination $^{\dagger}$} \\
\hline & $\begin{array}{c}1988 \\
(n=383) \\
\%(N o .)\end{array}$ & $\begin{array}{c}1990 \\
(\mathrm{n}=319) \\
\%(\text { No. })\end{array}$ & $\begin{array}{c}1995 \\
(\mathrm{n}=397) \\
\%(\mathrm{No} .)\end{array}$ & $\begin{array}{c}1990 \\
(\mathrm{n}=350) \\
\%(\mathrm{No})\end{array}$ & $\begin{array}{c}1995 \\
(n=350) \\
\%(N o .)\end{array}$ & $\begin{array}{c}1995 \\
(n=414) \\
\%(N o .)\end{array}$ \\
\hline $0-49$ & $24.0(92)$ & $8.2(26)$ & $2.8(11)$ & $6.3(22)$ & $6.3(22)$ & $5.8(24)$ \\
\hline $50-74$ & $17.2(6)$ & $8.8(28)$ & $5.3(21)$ & $11.7(41)$ & $10.9(38)$ & $13.3(55)$ \\
\hline $75-99$ & $21.7(83)$ & $32.0(102)$ & $28.2(112)$ & $26.3(92)$ & $27.1(95)$ & $26.1(108)$ \\
\hline 100 & $37.1(142)$ & $51.1(163)$ & $63.7(253)$ & $55.7(195)$ & $55.7(195)$ & $54.8(227)$ \\
\hline
\end{tabular}

${ }^{*} \chi^{2}=122.751 \mathrm{df}, P<.001$ (Mantel-Haenszel test for linear association).

${ }^{\dagger} \chi^{2}=0.071 d f$, ns (Mantel-Haenszel test for linear association).

cians reporting that they regularly refer all women aged 50 to 75 years for mammography, increasing from 37 percent in 1988 to 64 percent in 1995 (Table 2). On the other hand, the proportion indicating that they regularly performed clinical breast examination on all these patients remained remarkably stable at about 56 percent.

Table 2 also shows that during the 8-year period there was a reversal in terms of the most frequently performed screening method. In 1988 physicians more frequently reported performing clinical breast examination on all women aged 50 to 75 years than referral for mammography (difference of 19 percent), whereas in 1995 physicians more frequently reported referrals of all women in this age group for mammography than performance of clinical breast examination (difference of 9 percent). The findings were the same when we restricted the analysis to only those physicians who were known to have responded to the consecutive survey waves. The additional analysis performed on control group physicians to rule out potential bias relating to recollection of past interventions by physicians in the intervention group also revealed the same pattern of results. There was no statistically significant variation in mammography screen- ing rates by year since graduation from medical school or by practice type (eg, solo vs group).

In 1995 we also examined the physicians' level of agreement with statements about the two screening methods. Responses were measured on a 5 -point scale ranging from disagree strongly to agree strongly (Table 3 ). Physicians were more likely to disagree strongly with the statement suggesting clinical breast examination alone is sufficient ( 80 percent) than mammography alone is sufficient (68 percent) despite national recommendations that both screening methods be performed concurrently. More than 62 percent of physicians agreed that regularly performing clinical breast examinations on their patients was important to avoid malpractice claims (not shown).

As indicated in Table 4, one half of the physicians responding in 1995 cited that the woman did not come in for a routine visit as the most frequent reason for not ordering screening mammograms, whereas nearly one half ( 47 percent) said another physician refers the patient for mammography as the reason. Less frequently cited reasons for nonreferral were the patient is reluctant or anxious, she has no insurance or cannot afford a mammogram, or she has too many other health problems. Four

Table 3. Physician Level of Agreement With Statements About Screening Methods.

\begin{tabular}{lcccc}
\hline & $\begin{array}{c}\text { It is not important to spend much time on } \\
\text { screening clinical breast examinations because } \\
\text { mammograms detect most early cancers } \\
(\mathrm{n}=425)\end{array}$ & $\begin{array}{c}\text { Screening mammography does not contribute } \\
\text { information beyond that which can be } \\
\text { gained through physical examination } \\
(\mathrm{n}=424)\end{array}$ \\
\cline { 2 - 5 } Level of Agreement & Number & Percent & Number & Percent \\
\hline Disagree strongly & 289 & 68.0 & 339 & 80.0 \\
Disagree somewhat & 87 & 20.5 & 63 & 14.9 \\
Neutral & 32 & 7.5 & 8 & 1.9 \\
Agree somewhat & 6 & 1.4 & 7 & 1.7 \\
Agree strongly & 11 & 2.6 & 7 & 1.7 \\
\hline
\end{tabular}


Table 4. Frequency of Reasons for Not Ordering Screening Mammograms for Women Aged 50 to 75 Years.

\begin{tabular}{lcccc}
\hline Reasons for Not Ordering a Screening Mammogram & $\begin{array}{c}\text { Usually } \\
\text { No. (\%) }\end{array}$ & $\begin{array}{c}\text { Sometimes } \\
\text { No. (\%) }\end{array}$ & $\begin{array}{c}\text { Rarely } \\
\text { No. (\%) }\end{array}$ & $\begin{array}{c}\text { Never } \\
\text { No. (\%) }\end{array}$ \\
\hline She does not come in for a routine visit & $203(50.0)$ & $140(34.5)$ & $40(9.9)$ & $23(5.7)$ \\
Another physician refers her for mammography & $190(46.5)$ & $173(42.3)$ & $25(6.1)$ & $21(5.1)$ \\
She is reluctant or anxious. & $37(9.0)$ & $102(27.3)$ & $117(28.5)$ & $144(35.1)$ \\
She has no insurance, cannot afford mammogram & $11(2.7)$ & $72(17.7)$ & $140(34.5)$ & $183(45.1)$ \\
She has too many other health problems & $4(2.3)$ & $80(19.8)$ & $129(31.9)$ & $186(45.9)$ \\
Her previous mammograms have not been useful & $2(0.5)$ & $15(3.7)$ & $86(21.1)$ & $304(74.7)$ \\
The clinical breast examination is sufficient & $2(0.5)$ & $15(3.7)$ & $47(11.6)$ & $342(84.2)$ \\
Other & $9(15.8)$ & $7(12.3)$ & $10(17.5)$ & $31(54.4)$ \\
\hline
\end{tabular}

percent responded that they "usually" or "sometimes" do not refer for mammography because previous mammograms have not been useful, and another 4 percent because clinical breast examination is sufficient.

Table 5 displays physician agreement in the most recent survey with a series of statements concerning the elderly. More than 25 percent did not agree that the incidence of breast cancer increases with age, and less than one half agreed that breast cancer detection by mammography is enhanced in older women.

As indicated in Table 6, practically all physicians who responded to the 1995 survey recognized that a family (first-degree relative) or personal history of breast cancer are risk factors. The known breast cancer risk factors of older age, early menarche, late menopause, and a history of breast surgery were less frequently cited as risk factors than taking estrogen preparations and eating a high-fat diet (which are suspected risk factors because there is only mixed evidence of risk). Cigarette smoking, for which there is even less evidence of risk, was also more frequently cited as a risk factor than those that are known. Forty-two percent felt that exposure to pesticides or insecticides was a risk factor, although such compounds are as yet unproved and are currently being investigated.

We also explored physician confidence, as reported during the most recent survey, in a variety of aspects relating to breast cancer screening ranging from performance of the clinical breast exami-

Table 5. Level of Agreement With Statements Concerning the Elderly.

\begin{tabular}{|c|c|c|c|}
\hline Statement & $\begin{array}{l}\text { Agree } \\
\text { No. }(\%)\end{array}$ & $\begin{array}{l}\text { Neutral } \\
\text { No. }(\%)\end{array}$ & $\begin{array}{l}\text { Disagree } \\
\text { No. (\%) }\end{array}$ \\
\hline The incidence of breast cancer increases with age & $309(73.9)$ & $65(15.6)$ & $44(10.5)$ \\
\hline $\begin{array}{l}\text { A } 75 \text {-year-old woman in average health statistically is expected to live } \\
\text { another } 10-15 \text { years }\end{array}$ & $273(65.9)$ & $78(18.8)$ & $63(15.2)$ \\
\hline Breast cancer detection by mammography is enhanced in older women & $203(49.3)$ & $136(33.0)$ & $73(17.7)$ \\
\hline In general, elderly women tolerate breast cancer treatment well & $198(48.0)$ & $132(32.0)$ & $83(20.1)$ \\
\hline $\begin{array}{l}\text { Quality-of-life issues greatly affect the appropriateness of breast cancer } \\
\text { screening. }\end{array}$ & $135(33.1)$ & $90(22.1)$ & $183(44.9)$ \\
\hline $\begin{array}{l}\text { The biology of breast cancer in women }>65 \text { years is probably } \\
\text { no different from that in women } 50-65 \text { years }\end{array}$ & $113(27.4)$ & $105(25.4)$ & $195(47.2)$ \\
\hline $\begin{array}{l}\text { I would usually not order a screening mammogram for a } 70 \text {-year-old } \\
\text { woman with multiple medical problems }\end{array}$ & $50(11.8)$ & $73(17.2)$ & $308(71.0)$ \\
\hline $\begin{array}{l}\text { The average woman }>75 \text { years does not benefit from screening } \\
\text { mammograms }\end{array}$ & $41(9.6)$ & $81(19.1)$ & $303(71.3)$ \\
\hline $\begin{array}{l}\text { In women } \geq 65 \text { years, periodic screening mammography is appropriate } \\
\text { only when risk factors for breast cancer are present }\end{array}$ & $31(7.4)$ & $34(8.2)$ & $351(84.4)$ \\
\hline $\begin{array}{l}\text { Breast cancer is less curable in women }>65 \text { years than in women } \\
50-64 \text { years old }\end{array}$ & $23(5.6)$ & $67(16.2)$ & $323(78.2)$ \\
\hline
\end{tabular}

*On a 5-point scale ranging from "disagree strongly" to "agree strongly": 4 or $5=$ agree, $3=$ neutral, 1 or 2 = disagree. 
nation to counseling skills. Eighty-six percent of the physicians feel confident in performing clinical breast examination, and 73 percent in teaching selfbreast examination. More than 90 percent reported performing three components of the clinical breast examination: visual observation of the breast and palpation of the supra clavicular and axillary nodes in the sitting position, and palpation of the breasts in the supine position. Recommended palpation of the breasts in other positions were reported by less than 70 percent for the sitting position, and less than 30 percent in the oblique position.

Almost one half (46 percent) of the respondents agreed that, in general, primary care physicians need more education about how to manage suspicious mammography findings, while more than three quarters of them felt confident about interpreting the radiologist's report of a screening mammogram and how to address a woman's reluctance or other barriers to obtaining screening. Only about one half ( 51 percent) felt confident in recognizing cultural barriers to obtaining screening.

As far as office systems are concerned, about one third ( 33 percent) of respondents agreed that clerical and nursing staff in their office could do more to help their patients receive regular mammograms. About 72 percent reported that they teach breast self-examination. Nearly one half (49 percent) used provider reminder systems for ordering or doing mammography screening and clinical breast examinations, whereas 39 percent used patient reminders for breast cancer screening.

Although about three quarters of physicians felt well prepared to counsel patients about the effectiveness of clinical breast examination and mammography, more than 25 percent did not feel well prepared to counsel about sources of payment or cost of mammography. A large proportion felt only somewhat prepared to counsel about individual risk of breast cancer ( 50 percent) and fears and concerns about breast cancer ( 35 percent).

\section{Discussion}

In this study we tracked changes in the self-reported breast cancer screening practices of primary care physicians during the 8-year period of 1988 to 1995. Because we did not have access to the office medical records of the predominantly private practicing physicians surveyed, we could not validate these reports through chart audit. Nevertheless, there is substantial evidence in the literature that
Table 6. Physician Reporting of Risk Factors

for Breast Cancer.

\begin{tabular}{llc}
\hline & \multicolumn{2}{l}{ Physicians Responding } \\
\cline { 2 - 3 } Risk Factor & Number & Percent \\
\hline Known risk factors & & \\
Mother or sister with breast cancer & 420 & 99.5 \\
History of breast cancer & 408 & 96.7 \\
No children & 306 & 72.5 \\
First child at an older age & 261 & 61.8 \\
Did not breast-feed babies & 238 & 56.4 \\
First period at an early age & 234 & 55.5 \\
Previous breast surgery & 219 & 51.9 \\
Older age than average at menopause & 196 & 46.4 \\
Fibrocystic disease of the breast & 178 & 42.2 \\
Postmenopausal obesity & 167 & 39.6 \\
Suspected risk factors & & \\
Taking estrogen preparations & 249 & 59.0 \\
(eg, birth control pills) & & \\
High-fat diet & 240 & 56.9 \\
Drinking alcohol & 172 & 40.8 \\
Controversial risk factors* & & \\
Smoking cigarettes & 254 & 60.2 \\
Exposure to pesticides or insecticides & 178 & 42.2 \\
Living or working near high-tension & 108 & 25.6 \\
wires, transformers, or electric & & \\
power plants & 88 & 20.9 \\
Having injuries to the breast & & \\
\hline
\end{tabular}

"Includes items for which only sparse data are available, as well as items with extensive data but no evidence of an overall positive association (ie, smoking) but for which some claim there might be an association within subgroups.

physician self-reports falsely inflate the actual performance of screening as documented in medical records. ${ }^{9-11}$ In one such comparison it was noted that chart audits for documenting advice about or referrals for mammography might not be useful because these are not chargeable services and therefore might not be recorded in charts. ${ }^{10}$ While on the one hand this likely overestimation means that the levels of compliance as reported in our study should be viewed with caution, on the other hand it also means that the relatively low rates of reported mammography referral (62 percent) might in reality be even lower.

We found that rates of mammography referrals were not significantly related to practice type (solo versus group) or years since graduation from medical school. Other studies have reported similar findings for practice type. ${ }^{6}$ Findings for years since medical school graduation have been inconsistent, 
however, with some studies showing that more recently trained physicians are more likely to report higher rates of mammography referrals ${ }^{12,13}$ and others reporting no relation. ${ }^{14}$

Of interest was that despite a statistically significant increase from 1988 to 1995 in reported referral for mammography, there was no change in self-reported performance of clinical breast examination. Indeed clinical breast examination was reported to be routinely performed less frequently than referral for mammography in 1995, whereas the reverse was the case in 1988. This finding and physician's agreement with statements about screening indicate a growing confidence in the value of mammography versus clinical breast examination for breast cancer screening and suggest a decline in the combined use of both modalities, even though mammography alone is known to miss 10 to 15 percent of breast cancers and a combined approach is recommended. ${ }^{15}$

Because nearly one half ( 47 percent) of the physicians indicated that when they do not refer for mammography, it is usually because another physician makes the referral for their patient, it is possible that the rates of screening among their women patients are higher than would be projected from the family physician reports. Evidence from our women's survey conducted during 1989 indicated that women who reported visiting a gynecologist in addition to their family physician or internist had higher self-reports of mammography use than those reporting that they visit only a family physician or internist, although there was no increase if the second physician was not a gynecologist. ${ }^{3}$ In that survey visits to gynecologists dropped off rapidly with the advancing age of women, ranging from 49.5 percent among women 50 to 55 years of age to 12 percent among women 70 to 75 years old. Based upon that information, the increase in mammography by women using 2 physicians is likely to be modest and would still not approach desired goals based on national guidelines.

An increase in compliance with mammography screening guidelines without an increase in compliance with guidelines for breast examination was also found in the American Cancer Society (ACS) surveys. ${ }^{4}$ Rates of screening comparable to our own, as reported in the literature from the ACS national surveys ${ }^{4}$ and in other regions $s^{6,14,16-18}$ suggest that our findings might not be specific to Long Island.
A woman's lack of health insurance or inability to afford mammography continues to be cited as a deterrent to referral for mammography but at a much lower frequency than in previous studies, ${ }^{2}$ perhaps because of coverage through Medicare and state-mandated programs. Underinsured women still have relatively low rates of use. ${ }^{19,20}$ Yet more than a quarter of physicians surveyed felt unprepared to counsel patients about sources of payment and costs of mammography. Obtaining fee schedules from radiologists in the primary care physician's referral network and having available information on low-cost mammography (eg, through a health department) might be a helpful strategy. The most commonly reported reasons for not ordering screening mammograms were believed to be the patient's combined use of other physicians or her failure to appear for a routine visit, indicating the desirability of addressing this preventive service during acute care visits.

Evidence of lower mammography rates among women aged 65 years and older, despite the higher incidence of breast cancer in this age group, has been cited in the literature. ${ }^{1,3,15,21}$ Our findings indicate that more than 25 percent of physician respondents were unaware that breast cancer incidence increases with age, and more than one half did not recognize that breast cancer detection by mammography is enhanced in older postmenopausal women (higher positive predictive value). These findings, coupled with lack of awareness on the part of some physicians of the long life expectancy among older women, tolerance of breast cancer treatment by older women, and related quality-of-life concerns, suggest a need for greater attention to mammography screening of older women. Because the performance of clinical breast examination in this age group has been reported to be higher and the frequency of visits greater, these encounters continue to be missed clinical opportunities. ${ }^{1,22,23}$

Physician perception of breast cancer risk from proved and unproved risk factors for breast cancer are in keeping with the finding that only one half of the respondents felt somewhat prepared to counsel patients about individual risk, and suggest a need for continuing medical education in this area. More than three quarters of the physicians reported that they felt very confident in interpreting the radiologist's report, indicating some improvement in data obtained from our 
1990 survey in which about one half of the physicians indicated concern about equivocal radiology reports. ${ }^{2}$ This change could relate in part to efforts sponsored by the American College of Radiology to standardize the nomenclature used in preparing such reports and supports the development of their breast imaging reporting and data system. ${ }^{24}$

Nevertheless, nearly one half of the physician respondents agreed that they need education about how to manage suspicious mammography findings. Perhaps concern about the negative consequences of unnecessary biopsies or further diagnostic imaging studies on the one hand and risk of malpractice litigation on the other hand create a dilemma for the primary care physician that would benefit from greater specificity and direction by the radiologist in terms of indicated follow-up.

Physician self-reported lack of confidence in various aspects of screening related patient counseling and examination skills and low use of office systems point to the need for developing continuing medical education programs that specifically address such areas of perceived weakness. Two critical reviews of randomized controlled trials of continuing medical education interventions noted that, although widely used, conferences were found to have little direct impact on improving practice. ${ }^{25,26}$ Systematic practice-based enabling or reinforcing strategies and outreach visits (eg, academic detailing), and combined approaches were found to be effective, ${ }^{25-27}$ and there are successful reports of increasing breast cancer screening rates through continuing medical education. ${ }^{28}$ Our implementation and evaluation of such a targeted continuing education offering based upon this needs assessment will be the subject of future reports.

External reinforcements, such as peer review and comparison, are other strategies to promote physician behavior change. With increasing physician participation in managed care nationally, as on Long Island, reinforcement could in part be accomplished through monitoring preventive services delivered as a measure of quality of care by managed care organizations. Facilitating such an approach is the National Committee on Quality Assurance report card for managed care organizations, known as the Health Employer Data and Information Set measures, which include mammography screening rates. ${ }^{29}$
Roger Grimson, $\mathrm{PhD}$, provided a review of the statistical analysis.

\section{References}

1. Screening mammography: a missed clinical opportunity? Results of the NCI Breast Cancer Screening Consortium and National Health Interview Survey Studies. JAMA 1990;264:54-8.

2. Lane DS, Polednak AP, Burg MA. Effect of continuing medical education and cost reduction on physician compliance with mammography screening guidelines. J Fam Pract 1991;3:359-68.

3. Lane DS, Caplan LS, Grimson R. Trends in mammography use and their relation to physician and other factors. Cancer Detect Prev 1996;20:332-41.

4. American Cancer Society. 1989 survey of physicians' attitudes and practices in early cancer detection. CA Cancer J Clin 1990;40:70-101.

5. Weinberger $M$, Saunders AF, Samsa GP, Bearon LB, Gold DT, Brown JT, et al. Breast cancer screening in older women: practices and barriers reported by primary care physicians. J Am Geriatr Soc 1991; 39:22-9.

6. Roetzheim RG, Fox SA, Leake B. Physician-reported determinants of screening mammography in older women: the impact of physician and practice characteristics. J Am Geriatr Soc 1995;43:1398-402.

7. Mantel N. Chi-square tests with one degree of freedom: extensions of the Mantel-Haenszel procedure. J Am Statist Assoc 1963;58:690-700.

8. Statistical package for the social sciences, version 6.1 for windows. Chicago: SPSS, 1994.

9. McPhee SJ, Richard RJ, Solkowitz SN. Performance of cancer screening in a university general internal medicine practice: comparison with 1980 American Cancer Society Guidelines. J Gen Intern Med 1986; 1:275-81.

10. Montano DE, Phillips WR. Cancer screening by primary care physicians: a comparison of rates obtained from physician self-report, patient survey, and chart audit. Am J Public Health 1995;85:795-900.

11. Fox SA, Klos DS, Tsou CV. Underuse of screening mammography by family physicians. Radiology 1988;166:431-3.

12. Bergner M, Allison CJ, Doehr P, Ford LG, Feigl P. Early detection and control of cancer in clinical practice. Arch Intern Med 1990;150:431-6.

13. Albanes D, Weinberg GB, Boss L, Taylor PR. A survey of physicians' breast cancer early detection practices. Prev Med 1988;17:643-52.

14. Turner BJ, Amsel Z, Lustbader E, Schwartz JS, Balshem A, Grisso JA. Breast cancer screening: effect of physician specialty, practice setting, year of medical school graduation, and sex. Am J Prev Med 1992; 8:78-85.

15. Bassett LW, Butler DL. Mammography and early breast cancer detection. Am Fam Physician 1991; 
43:547-57.

16. Taylor VM, Montano DE, Koepsell T. Use of screening mammography by general internists. Cancer Detect Prev 1994;18:455-62.

17. Rimer BK, Trock B, Balshem BA, Engstrom PF, Rosen J, Lerman C. Breast screening practices among primary physicians: reality and potential. $J$ Am Board Fam Pract 1990;3:26-4.

18. Deitrich AJ, O'Connor GT, Keller A, Carney PA, Levy D, Whaley FS. Cancer: improving early detection and prevention. A community practice randomized trial. BMJ 1992;304:687-91.

19. Urban N, Anderson GL, Peacock S. Mammography screening: how important is cost as a barrier to use? Am J Public Health 1994;84:50-5.

20. Zapka JG, Stoddard AM, Costanza ME, Greene HL. Breast cancer screening by mammography: utilization and associated factors. Am J Public Health 1989;79:1499-502.

21. Costanza ME, Stoddard A, Gaw VP, Zapka JG. The risk factors of age and family history and their relationship to screening mammography utilization. J Am Geriatr Soc 1992;40:774-8.

22. Breen N, Kessler $L$. Changes in the use of screening mammography: evidence from the 1987 and 1990 National Health Interview Surveys. Am J Public
Health 1994;84:62-7.

23. Burg M, Lane DS, Polednak AP. Age group differences in the use of breast cancer screening tests: the effect of health care utilization and socioeconomic variables. J Aging Health 1990;2:514-530.

24. Breast imaging reporting and data system (BIRADS), 2nd ed. Reston, Va: American College of Radiology, 1995.

25. Davis DA, Thomson MA, Oxman AD, Haynes RB. Changing physician performance. A systematic review of the effect of continuing medical education strategies. JAMA 1995;274:700-5.

26. Oxman $\mathrm{AD}$, Thomson MA, Davis DA, Haynes RB. No magic bullets: a systematic review of 102 trials of intervention to improve professional practice. CMAJ 1995;153:1423-31.

27. Davis DA, Thomson MA, Oxman AD, Haynes RB. Evidence for the effectiveness of CME. A review of 50 randomized control trials. JAMA 1992;268:1111-7.

28. Deitrich AJ, Barrett J, Levy D, Carney-Gersten P. Impact of an educational program on physician cancer control knowledge and activities. Am J Prev Med 1990;6:346-52.

29. HEDIS 3.0: health employer data \& information set. Washington, DC: National Committee for Quality Assurance, 1996. 